\title{
Mutation Analysis of KRAS and BRAF Genes in Metastatic Colorectal Cancer: a First Large Scale Study from Iran
}

\author{
Aghigh koochak ${ }^{1}$, Nasser Rakhshani ${ }^{*}$, Mohammad Hadi Karbalaie Niya ${ }^{2}$, \\ Fahimeh Safarnezhad Tameshkel ${ }^{1}$, Masoud Reza Sohrabi ${ }^{1}$, Mohammad Reza \\ Babaee $^{1}$, Hamid Rezvani ${ }^{3}$, Babak Bahar ${ }^{1}$, Farid Imanzade ${ }^{4}$, Farhad Zamani ${ }^{1}$, \\ Mohammad Reza Khonsari ${ }^{1}$, Hossein Ajdarkosh ${ }^{1}$, Gholamreza Hemmasi ${ }^{1}$
}

\begin{abstract}
Background: The investigation of mutation patterns in oncogenes potentially can make available a reliable mechanism for management and treatment decisions for patients with colorectal cancer (CRC). This study concerns the rate of KRAS and BRAF genes mutations in Iranian metastatic colorectal cancer (mCRC) patients, as well as associations of genotypes with clinicopathological features. Materials and Methods: A total of 1,000 mCRC specimens collected from 2008 to 2012 that referred to the Mehr Hospital and Partolab center, Tehran, Iran enrolled in this cross sectional study. Using HRM, Dxs Therascreen and Pyrosequencing methods, we analyzed the mutational status of KRAS and BRAF genes in these. Results: KRAS mutations were present in $33.6 \%$ cases $(n=336)$. Of KRAS mutation positive cases, $85.1 \%$ were in codon 12 and $14.9 \%$ were in codon 13 . The most frequent mutation at KRAS codon 12 was Gly12Asp; BRAF mutations were not found in any mCRC patients $(n=242)$. In addition, we observed a strong correlation of KRAS mutations with some clinicopathological characteristics. Conclusions: KRAS mutations are frequent in mCRCs while presence of BRAF mutations in these patients is rare. Moreover, associations of KRAS genotypes with non-mucinous adenocarcinoma and depth of invasion (pT3) were remarkable.
\end{abstract}

Keywords: Mutation analysis - KRAS - BRAF - metastatic colorectal cancer, pyrosequencing - high resolution melting

Asian Pac J Cancer Prev, 17 (2), 603-608

\section{Introduction}

Colorectal cancer (CRC) is one of the most frequent cancer types worldwide, with more than 70,000 new affected per year in the United States (Fransen et al., 2004, Jemal et al., 2011). CRC progresses through a multi-step carcinogenic process with a gathering of epigenetic and genetic alterations, including KRAS and BRAF mutation (Imamura et al., 2012). The KRAS proto-oncogene encodes a GTPase which trigger signal transduction cascade of Influence of epidermal growth factor receptor/mitogen-activated protein kinases (EGFR/ MAPK pathway), resulting in recruits and activates BRAF (Campbell et al., 1998, Fransen et al., 2004, Guedes et al., 2013). BRAF, another factor of the EGFR/MAPK signaling pathway, produces a serine-threonine protein kinase that is a downstream molecule of actuated KRAS (Chen et al., 2014). BRAF mutant induces a signaling cascade involving factors in the MAPKs, resulting in cell propagation (Allegra et al., 2009, Guedes et al., 2013).
It has been demonstrated that mutation of KRAS and BRAF genes frequently observed in the early stages of CRC (Roth et al., 2010). Approximately $30 \%$ to $40 \%$ of CRC tissues harbor a mutated KRAS gene (Andreyev et al., 1998; Andreyev et al., 2001), and 90\% of those mutations found in exon 2 of the KRAS gene (at codons 12/13) (Janakiraman et al., 2010, De Roock et al., 2011). This mutant gene create a constitutively active ras factor that leads to EGFR-independent activation of the MAPK signaling pathway (Bos et al., 1987; Bamford et al., 2004) and subsequent induces cell growth and resistance to apoptosis (Rajagopalan et al., 2002; Benvenuti et al., 2007; Schubbert et al., 2007). Recent studies have shown that Almost $15 \%$ of CRC harbor the BRAF mutation (Deng et al., 2004; Roth et al., 2010) and approximately all BRAF-mutated CRC are existing within the KRAS wild-type cancers (Imamura et al., 2012). Mutations of the KRAS gene have been broadly studied as prognostic biomarkers for CRC (Hsieh et al., 2012). On the other hand the BRAF mutation has been correlated with lesser

${ }^{1}$ Gastrointestinal and Liver Diseases Research Center, Firoozgar Hospital, ${ }^{2}$ Department Of Virology, Iran University Of Medical Sciences, ${ }^{3}$ Department of Oncology, ${ }^{4}$ Department of Pediatrics, Shahid Beheshti University of Medical Sciences, Tehran, Iran *For correspondence: n_rakhshani@yahoo.com 


\section{Aghigh Kochak et al}

prognosis in several studies (French et al., 2008; FarinaSarasqueta et al., 2010; Roth et al., 2010). However, mutation analysis of KRAS and BRAF genes, as members of EGFR/MAPK pathway, before the administration of anti-EGFR-targeted therapies for patients with CRC has become important (Rizzo et al., 2010). In CRCs, population-based investigations have proposed that the mutations might be correlated with some tumor features (Hsieh et al., 2012). However, the mutation rate and clinicopathological characteristics of KRAS/BRAF genes in Iranian CRC patients stay has been unclear. The aim of our study was to investigate the mutational activation of two members of the MAPK pathway, the KRAS gene in $1000 \mathrm{mCRC}$ and BRAF gene in $242 \mathrm{mCRC}$ tissue at stage IV in Iranian population by using HRM and Pyrosequencing techniques.

\section{Materials and Methods}

\section{Study population}

The biopsy specimens were obtained from 1000 Iranian mCRC patients including $427(42.7 \%)$ female (median age 55 yrs.) and 573 (57.3\%) male (median age $57 \mathrm{yrs}$.); their pathological data are listed in Table 1. These patients between 2008 and 2012 were referred to the Mehr Hospital and molecular diagnostic laboratory of Partolab, the main referral center for cancerous patients in Iran that located in Tehran, Iran. Written informed consent was obtained from all patients before testing. The study was approved by the ethical committee of Iran University of Medical sciences, Tehran, Iran.

Hematoxylin and Eosin (H\&E)-stained slides from all CRC cases were reviewed by a sophisticated pathologist and at least $50 \%$ neoplastic tissues selected for mutation analysis. Unstained slides were immersed in xylene for 5 minutes and twice in ethanol $100 \%$ for 5 minutes. Tumor areas were then delimited, by comparison with correspondent H\&E stained slides, and macro dissected.

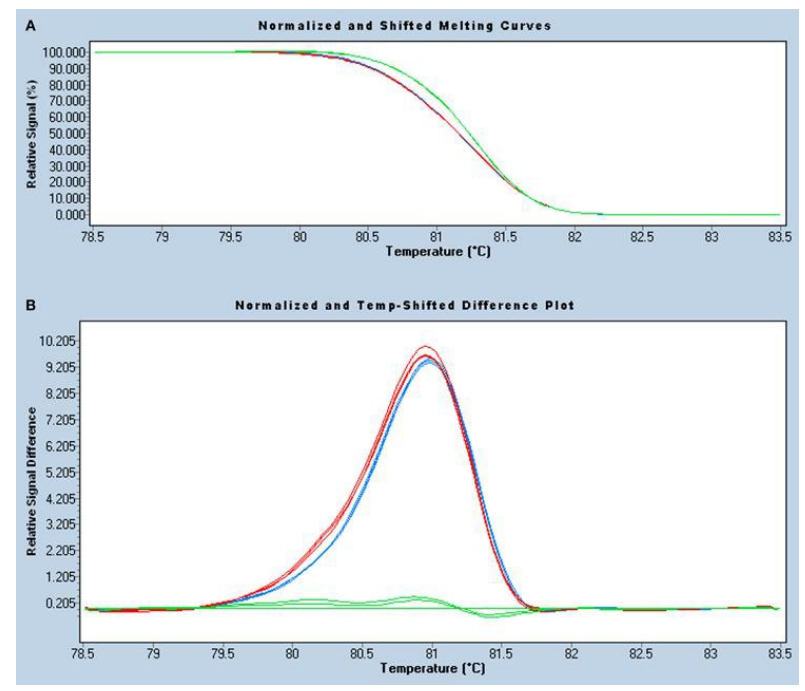

Figure 1. HRMA Melting Profiles Obtained from Tissues Carrying Mutant KRAS. The figure shows the results of Gene Scanning analyses. A) Normalized and B) difference graph, containing wild-type samples (green) and mutated samples (blue and red)

\section{DNA extraction}

Genomic DNA was extracted from dissected tissue using the methods described by the QIAamp ${ }^{\circledR}$ DNA FFPE Tissue Kit (QIAGEN, Hilden, Germany). Concentration (ng/ul) and purity (OD 260/280nm) of DNA was quantified by spectrophotometry with NanoDrop ND- $1000^{\circledR}$ (Thermo Fisher Scientific Inc., Waltham, MA, USA). Extracted DNA was stored at $-20^{\circ} \mathrm{C}$ before use.

\section{High resolution melting (HRM)}

To distinguish KRAS and or BRAF mutant from wild-type specimens, High resolution melting (HRM) was performed as a screening method. PCR amplification and HRM were performed on a LightCycler ${ }^{\circledR} 480$ II RealTime System (Roche Diagnostics, Basel, Switzerland). Analysis provided with the software LightCycler ${ }^{\circledR} 480$ Gene Scanning Software Version 1.5 (Roche diagnostics) (Figure1). PCR reaction mixtures with a final volume of 10 $\mu \mathrm{l}$ contained: The $0.5 \mu \mathrm{M}$ forward primer, $0.5 \mu \mathrm{M}$ reverse primer, $0.5 \mu \mathrm{M}$ unlabelled probe with a 3'-conjugated C3 spacer, $0.01 \mu$ g genomic DNA in $1 \times$ LightScanner Master mix (Idaho Technologies, Salt Lake City, UT, USA). Assay for KRAS performed by following program: one cycle of initial denaturation at $95^{\circ} \mathrm{C} 2 \mathrm{~min} ; 50$ cycles of $30 \mathrm{~s}$ $95 \mathrm{oC}$ (denaturation); $30 \mathrm{~s} 64^{\circ} \mathrm{C}$ (annealing); $30 \mathrm{~s} 72^{\circ} \mathrm{C}$ (extension); and one cycle of $60 \mathrm{~s} 72^{\circ} \mathrm{C}, 20 \mathrm{~s} 95^{\circ} \mathrm{C}, 20 \mathrm{~s}$ $55^{\circ} \mathrm{C}$; final melting in two steps follows: Melt $1(55-78 \mathrm{oC}$ at $0.06 \mathrm{oC} / \mathrm{s})$ followed by Melt $2\left(78-95^{\circ} \mathrm{C}, 0.06^{\circ} \mathrm{C} / \mathrm{s}\right)$ and recorded of the fluorescent level. The termocycler conditions for BRAF HRM assay were: $95^{\circ} \mathrm{C} 10 \mathrm{~min}$; 40 cycles of $20 \mathrm{sec} 90^{\circ} \mathrm{C}, 20 \mathrm{sec} 67^{\circ} \mathrm{C}, 20 \mathrm{sec} 72^{\circ} \mathrm{C}$; a final extension at $72^{\circ} \mathrm{C} 10 \mathrm{~min}$. The heteroduplex cycle performed at $95^{\circ} \mathrm{C} 5 \mathrm{~min}$ and $40^{\circ} \mathrm{C} 1 \mathrm{~min}$, then, melting at $70^{\circ} \mathrm{C}$ to $90^{\circ} \mathrm{C}$ with 25 acquisitions $/{ }^{\circ} \mathrm{C}$ and a 1 minute cooling to $40^{\circ} \mathrm{C}$ with a ramp rate of $2.2^{\circ} \mathrm{C} /$ second.

The LightCycler software plotted the melting peak of the fluorescent signal corresponding to the temperature
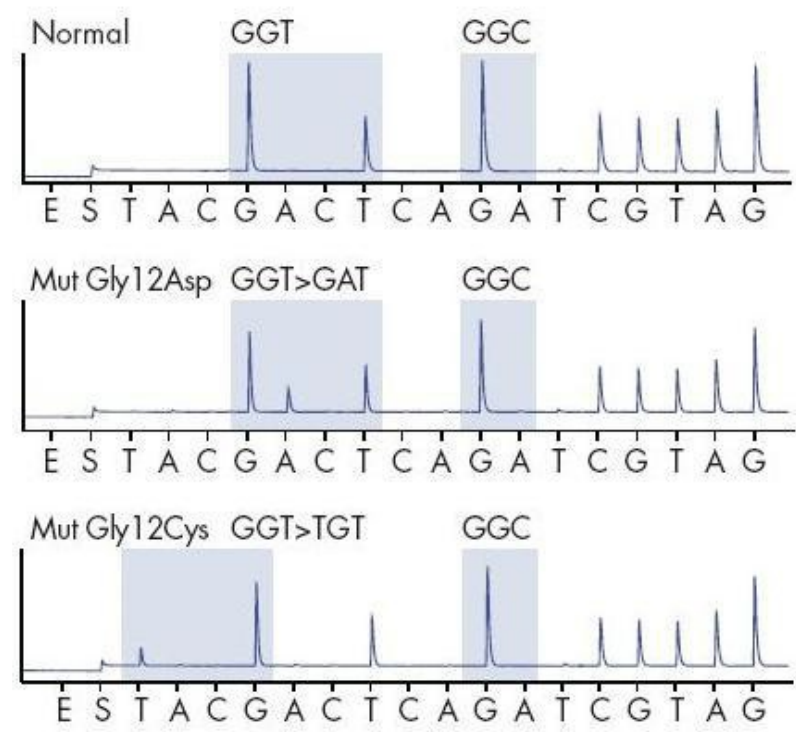

Figure 2. Pyrosequencing Electropherogram of Wild Type (Normal) and Mutant KRAS. (top) Wild type(12Gly-GGT, 13Gly-GGC), (middle and bottom) Mutant-KRAS (12Asp-GAT, 12Cys-TGT) 
Mutation Analysis of KRAS and BRAF Genes in Metastatic Colorectal Cancer: a First Large Scale Study from Iran.

$(-\mathrm{dF} / \mathrm{dT})$. The comparison of each patient's peak plot with WT (i.e. DNA isolated from human foreskin keratinocytes) and mutant (i.e. DNA isolated from cell lines HCT116 or Calu-1) reference DNA KRAS and or BRAF mutations identified.

\section{Pyrosequencing}

Extracted DNA samples were amplified for codons 12 and 13 of KRAS gene using primers from the PyroMark KRAS v.2.0 Q96 kit using Veriti 96 well Applied BioSystem thermal cycler. PCR reactions for KRAS codons 12 and 13 were performed under the following condition: the mixture was heated at $95^{\circ} \mathrm{C} 5 \mathrm{~min}, 45$ cycles of $95^{\circ} \mathrm{C} 15 \mathrm{~s}, 57^{\circ} \mathrm{C} 30 \mathrm{~s}, 72^{\circ} \mathrm{C} 15 \mathrm{~s}$. then, held at $72^{\circ} \mathrm{C} 5$ min. PCR components final concentrations were: 1x PCR buffer, $2 \mathrm{mM} \mathrm{MgCl}$ 2, 0.125 mM dNTPs, $0.2 \mu \mathrm{M}$ Forward primer and $0.2 \mu \mathrm{M}$ Reverse biotinylated primer, $1 \mathrm{U}$ of AmpliTaq polymerase (Perkin Elmer, Waltham, USA) and $2 \mathrm{ng} / \mu \mathrm{l}$ DNA template.

BRAF was accomplished in those samples considered positive by HRM (like KRAS), in order to confirmation of HRM analysis results. After HRM analysis profile, Pyrosequencing was carried out using the Qiagen

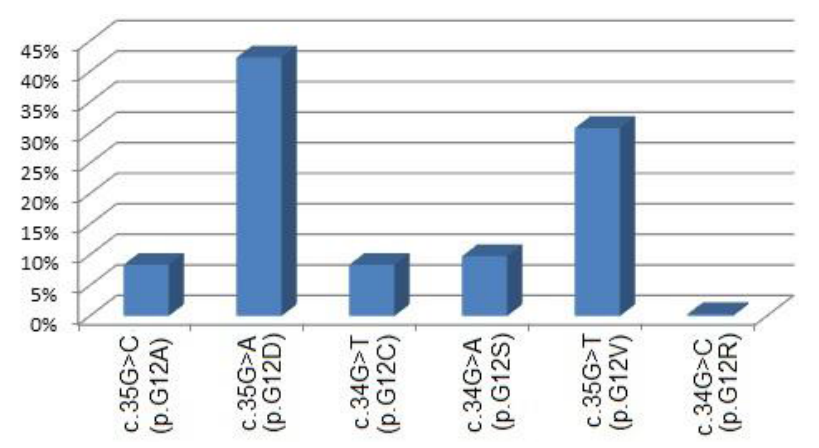

Figure 3. Frequency Distribution of the Different Mutation types Found in KRAS
PyroMark BRAF kit according to the manufacturer protocol. Sequencing primers for BRAF codon 600 were obtained from the PyroMarkBraf v.2.0 kit. Sequence analysis was conducted using the PyroMark Q96 software.

Running of $12 \mu \mathrm{l}$ PCR product on $1.5 \%$ agarose gel (Sigma-Aldrich, St. Louis, USA) used to confirm successful amplification. PyroMark Q96 analysis Software used to analysis of sequenced PCR products by EpigenDX Company (Worcester, USA). Purification of PCR products performed by illustra GFX PCR DNA and Gel Band Purification Kit (GE Healthcare, Little Chalfont, UK), according to manufacturer instructions.

Sequencing PCR products were run by $1 \mu \mathrm{L}$ of purified PCR amplification products on an PyroMark ID Pyrosequencing machine (QIAGEN, Germany) according to kit protocol, and the respective electropherograms were analyzed with PyroMark Q96 analysis Software (QIAGEN, Germany) (Figure2). All electropherograms were read manually.

\section{Dxs Therascreen}

TheraScreen DxS KRAS Mutation Kits KR-21 and KR-22 (QiaGen, Hilden, Germany) that were designed to detect six mutations in codon 12 (Gly > Ala, Asp, Arg, Cys, Ser, and Val) and one in codon 13 (Gly > Asp) of the KRAS oncogene. Internal reaction control and a synthetic control template were into commercial test kit. Calculation of the KRAS mutation degree were the difference between the control reaction and the allele-specific reaction. Two characteristics of its primers: $3^{\prime}$ ends were sequence-specific to detect mutations (comprise the PCR-Amplification Refractory Mutation System, PCRARMSW), and Real-time PCR-Scorpion W primer tags, that into double-stranded DNA were fluoresce emission.

LightCyclerW480 II (Roche Applied Science, Penzberg, Germany) used for PCR reactions corresponding to manufacturer protocol (TheraScreen K-RAS Mutation

Table 1. Demographical and Pathological Characteristics of CRC Patients

\begin{tabular}{llrr}
\hline Clinical and pathological characteristics & & $\mathrm{N}$ & $\%$ \\
\hline Sex & Male & 573 & 57.3 \\
Age (y) & Female & 427 & 42.7 \\
\multirow{3}{*}{ Tumor type } & $\leq 50$ & 325 & 32.5 \\
& $>50$ & 675 & 67.5 \\
\multirow{4}{*}{ Tumor differentiation } & Non Mucinous adenocarcinoma & 898 & 89.8 \\
& Mucinous adenocarcinoma & 86 & 8.6 \\
& Signet ring cell adenocarcinoma & 16 & 1.6 \\
pT (Depth of invasion) & Well Differentiated & 439 & 38.9 \\
& Moderate Differentiated & 384 & 16.4 \\
& Poor differentiated & 164 & 1.3 \\
& Undifferentiated & 13 & 1.4 \\
Lymph nodes involvement & p Tis & 14 & 1.4 \\
& p T1 & 14 & 5.3 \\
Pathological Grade & p T2 & 53 & 81.2 \\
& p T3 & 812 & 10.7 \\
& p T4 & 107 & 66.7 \\
\hline
\end{tabular}


Table 2. Frequency of KRAS Mutations According to Clinical and Pathological Features

\begin{tabular}{|c|c|c|c|c|c|}
\hline \multicolumn{2}{|c|}{ Clinical and pathological characteristics } & \multirow{3}{*}{$\begin{array}{l}\text { KRAS wild type } \\
\qquad \begin{array}{c}\text { N }(\%) \\
402(60.5 \%)\end{array}\end{array}$} & \multicolumn{3}{|c|}{ KRAS mutant, N (\%) } \\
\hline & & & \multirow{2}{*}{$\frac{\text { Total }}{171(50.9 \%)}$} & Codon 12 & \multirow{2}{*}{$\frac{\text { Codon } 13}{28(16.4 \%)}$} \\
\hline Sex & Male & & & $143(83.6 \%)$ & \\
\hline & Female & $262(39.4 \%)$ & $165(49.1 \%)$ & $143(86.7 \%)$ & $22(13.3 \%)$ \\
\hline \multirow[t]{2}{*}{ Age $(y)$} & $\leq 50$ & $235(35.4 \%)$ & $90(26.8 \%)$ & $74 \quad(82.3 \%)$ & $16(17.7 \%)$ \\
\hline & $>50$ & $429(64.6 \%)$ & $246(73.2 \%)$ & $212(86.2 \%)$ & $34(13.8 \%)$ \\
\hline \multirow[t]{3}{*}{ Tumor type } & Non-Mucinous adenocarcinoma & $602(90.7 \%)$ & $298(88.7 \%)$ & $250 \quad(83.9 \%)$ & $48(16.1 \%)$ \\
\hline & Mucinous adenocarcinoma & $46(6.9 \%)$ & $38(11.3 \%)$ & $34(89.5 \%)$ & $4(10.5 \%)$ \\
\hline & Signet ring cell adenocarcinoma & $16(2.4 \%)$ & $0 \quad(0.0 \%)$ & $0 \quad(0.0 \%)$ & $0 \quad(0.0 \%)$ \\
\hline Tumor & Well Differentiated & $265(39.9 \%)$ & $173(51.5 \%)$ & $77(44.5 \%)$ & $96(55.5 \%)$ \\
\hline \multirow[t]{3}{*}{ differentiation } & Moderate Differentiated & $279(42.0 \%)$ & $108(32.1 \%)$ & $86(79.6 \%)$ & $22(20.4 \%)$ \\
\hline & Poor differentiated & $109(16.4 \%)$ & $54(16.1 \%)$ & $39(72.2 \%)$ & $15(27.8 \%)$ \\
\hline & Undifferentiated & $11(1.7 \%)$ & $1(0.3 \%)$ & $1(100.0 \%)$ & $0 \quad(0.0 \%)$ \\
\hline \multirow{5}{*}{$\begin{array}{l}\text { pT (Depth of } \\
\text { invasion) }\end{array}$} & $\mathrm{p}$ Tis & $0 \quad(0.0 \%)$ & $14(4.2 \%)$ & $14(100.0 \%)$ & $0 \quad(0.0 \%)$ \\
\hline & $\mathrm{p} \mathrm{T1}$ & $14 \quad(2.1 \%)$ & $0(0.0 \%)$ & $0 \quad(0.0 \%)$ & $0 \quad(0.0 \%)$ \\
\hline & $\mathrm{p} \mathrm{T} 2$ & $33(5.0 \%)$ & $20(5.9 \%)$ & $13(65.0 \%)$ & $7(35.0 \%)$ \\
\hline & $\mathrm{p} \mathrm{T3}$ & $547(82.4 \%)$ & $265(78.9 \%)$ & $201 \quad(75.8 \%)$ & $64(24.2 \%)$ \\
\hline & p T4 & $70(10.5 \%)$ & $37(11.0 \%)$ & $33(89.2 \%)$ & $4(10.8 \%)$ \\
\hline \multirow{3}{*}{$\begin{array}{l}\text { Lymph nodes } \\
\text { involvement } \\
\text { Total mCRC }\end{array}$} & Involved & $399(60.1 \%)$ & $268(79.7 \%)$ & $239 \quad(89.2 \%)$ & $29(10.8 \%)$ \\
\hline & Uninvolved & $265(39.9 \%)$ & $68(20.3 \%)$ & $58 \quad(85.3 \%)$ & $10(14.7 \%)$ \\
\hline & 1000 patients & $664(66.4 \%)$ & $336(33.6 \%)$ & $286(85.1 \%)$ & $50(14.9 \%)$ \\
\hline
\end{tabular}

Table 3. Mutations Found in Exon 2 of the KRAS Gene (in Codons 12/13)

\begin{tabular}{lcccc}
\hline Gene Codon Analyte & \multicolumn{3}{c}{ Detected mutations } \\
\hline KRAS 12 & G12A & Gly12Ala & c.35G $>$ C & GGT $>$ GCT \\
& G12C Gly12Cys & c.34G $>$ T & GGT $>$ TGT \\
& G12D & Gly12Asp & c.35G $>$ A & GGT $>$ GAT \\
& G12F & Gly12Phe & c.34_35GG $>$ TT & GGT $>$ TTT \\
& G12R & Gly12Arg & c.34G $>$ C & GGT $>$ CGT \\
& G12S & Gly12Ser & c.34G $>$ A & GGT $>$ AGT \\
& G12V & Gly12Val & c.35G $>$ T & GGT $>$ GTT \\
13 & G13D & Gly13Asp & c.38G $>$ A & GGT $>$ GAC \\
\hline
\end{tabular}

Kit version DU001PE), by the using of $25 \mu$ l total reaction volume. The termocycler heating program were: $95^{\circ} \mathrm{C}$ for 4 min for initial denaturation, 45 cycles of $95^{\circ} \mathrm{C} 30 \mathrm{sec}$ and $60^{\circ} \mathrm{C} 1 \mathrm{~min}$. LightCycler Analysis Software 1.5.0 SP3 program (Roche Applied Science, Penzberg, Germany) used to data analysis.

\section{Statistical analysis}

SPSS version 20 software (SPSS Inc., Chicago, IL, USA) was used for statistical analyses and the basic descriptive and frequency features were used. After the calculation of arithmetic and standard mean, doublesided chi square/fisher-exact tests and t tests were used to compare genotype frequency and incidence between the various groups. $\mathrm{P}$ values less than 0.05 were considered to be statistically significant.

\section{Results}

\section{Patient characteristics}

A total of 1000 Iranian mCRC patients tested for KRAS mutations and 242 subsets (mCRC tissue at stage IV) of them analyzed for BRAF mutations using HRM, Pyrosequencing and TheraScreen DxS methods, respectively. Table 2 characterizes the results by more details.

\section{Frequency of KRAS mutations}

We found a mutation of KRAS (codon 12 or 13) in $33.6 \%$ cases $(n=336)$. Of KRAS mutation positive cases $85.1 \%$ were codon 12 mutant and $14.9 \%$ were codon 13 mutant (Table 1). The most common mutation at KRAS codon 12 was Gly12Asp, as shown in Figure 3. Other mutations founded in codon 12 were Gly 12Val, Gly12Ser, Gly12Ala, Gly12Cys and Gly12Arg. Also the most frequent mutation at codon 13 was Gly12Asp. All detected mutations of KRAS in our study have been previously described as oncogenic (table3). None of the KRAS mutation positive cases had BRAF mutation, respectively.

\section{Frequency of BRAF mutations}

We analyzed the mutational status of BRAF gene, using HRM and Pyrosequencing methods. Among 242 patients of our mCRC specimens, BRAF mutations were not detected. According to our results the BRAF mutation occurs at very low frequency in mCRC.

\section{Associations of Clinicopathological feature with KRAS mutations}

We analyzed whether KRAS genotypes correlated with any distinguishing clinicopathological and morphological features, including sex, age of patients, histological findings, depth of invasion (pT) and Lymph nodes involvement. Our results, as shown in table 2, indicate that KRAS mutations occurred at a statistically higher frequency in older patients $(>50)$ than in younger patients $(\leq 50)(\mathrm{P}=0.0001)$. Further statistical tests revealed that KRAS mutations have a tendency to occur in Nonmucinous adenocarcinoma than other tumor types $(\mathrm{P}=0.0001)$. In addition, there was a significant association of KRAS genotype with depth of invasion, so that KRAS mutations occur at a high rate in pT3 than pTis, pT1, pT2 and pT4 $(\mathrm{P}=0.0001)$. It is also worth mentioning that KRAS mutation tended to occur at a more frequency in male cases than in female cases, according to results of 
current study. But this was not a significant difference $(\mathrm{P}=0.7)$.

\section{Discussion}

Dramatic increasing in colorectal cancer (CRC) occurrence over the last thirty years in Iranian population made it a main public health problem (Dolatkhah et al., 2015). Actually, CRC is the fourth most common cancer of Iranian society (Mahdavinia et al., 2005) with probable number of 3641 new cases annually, from which 2262 died each year, accounting for almost $6.3 \%$ of all cancer deaths (Malekzadeh et al., 2009). The discovering of mutation patterns in oncogenes and tumor suppressor genes (TSGs) potentially can provide a reliable instrument on patient management and treatment strategies in CRC. The aim of our study was to examine the mutations rate of KRAS and BRAF genes in 1000 and 242 Iranian population of $\mathrm{mCRC}$ patients, respectively, in addition to evaluation of association value between genotypes of interested genes and clinicopathological features. To our knowledge, the current study is the first report on the frequency of KRAS and BRAF mutations from a largest sample size of metastatic colorectal cancers in Iranian population. We here show that BRAF mutations were not detected in any of the mCRC tissues analyzed, despite the high frequency of KRAS mutations in these lesions. Our analysis demonstrated that KRAS mutation was occurred in around $33.6 \%$ of CRC cases, which included $85.1 \%$ of cases with mutations at codon 12 and $14.9 \%$ of cases with mutations at codon 13. Since, it appears that Mutations in KRAS codons 12 and 13 are the almost frequently reported mutations in CRC patients (Vaughn et al., 2011). These results confirm previous reports regarding high rate and important role of KRAS mutations in CRC (Spindler et al., 2009). Furthermore, the rate of KRAS mutations in Iranian population is almost similar to reported rate of 36\% from European countries (Ciardiello et al., 2011). This rate in Japan and China is almost 38\% (Kadowaki et al., 2015, Ye et al., 2015). Although, these results differ from some published reported data on frequencies rate of KRAS mutations in CRC patients from Middle east populations (24\%), interestingly (Ciardiello et al., 2011, Negru et al., 2014). There are several possible explanations like ecological and lifestyle differences between the populations or diversity of genetic backgrounds (Negru et al., 2014). Also these difference results can be explained by variable samples size in considered research.

In 2008, Simi L and et al. published a paper in which they determine rate of approximately $9.5 \%$ for mutant BRAF in CRCs patients from Italian population (Simi et al., 2008). Saridaki Z and coworkers (Saridaki et al., 2011) analyzed the data from 112 CRC patients in the Greece and concluded the rate of BRAF mutations is $7.2 \%$ in the Spanish population, studies reported the BRAF mutational rate ranges from $6.25 \%$ to $13 \%$ in CRC patients (Borras et al., 2011; Herreros-Villanueva et al., 2011). In Chinese (Li et al., 2011), Korean (Kwon et al., 2011) and Thai (Hsieh et al., 2012) populations, frequency of mutant BRAF in CRCs is $7 \%, 3.3 \%$ and $1.1 \%$, respectively. The overall BRAF mutational frequency ranges from
$3.3 \%$ to $13 \%$ in the different ethnic groups (Hsieh et al., 2012), But no such rate could be observed in our study and we determine all of Iranian mCRC grade IV patients contain wild type BRAF gene. This finding of the current study are consistent with those of Naghibalhossaini and zamani who found no V600E mutation of BRAF gene in Iranian population (Naghibalhossaini et al., 2011). It is challenging to explain this result, but it might be related to geographical variation and different ethnic groups (Yokota et al., 2011). Although the sample size in our study is reliable, however, it is suggested that further research be undertaken. In accordance to reported results in the previous literature (Rajagopalan et al., 2002; Ahlquist et al., 2008; Amado et al., 2008), KRAS and BRAF mutations are mutually exclusive in CRCs. Similarly, our results support this hypothesis and shown that none of the 336 CRCs with KRAS mutations were not coexistent with the mutation in BRAF.

In order to association investigation of clinicopathological characteristics with KRAS genotypes, we also collected and analyzed the information on patient's sex and age, tumor type, tumor differentiation, lymph nodes involvement and depth of invasion. There are a statistically significant association between KRAS mutations and older patients (more than 50 years) $(\mathrm{P}=0.0001)$. These observations suggested that KRAS gene is more disposed to the mutation with increasing of age. We also found that KRAS mutations occurred at a statistically higher frequency in non-mucinous adenocarcinoma $(\mathrm{P}=0.0001)$, and pT3 $(\mathrm{P}=0.0001)$. These data proposed that KRAS mutations might related to crucial event favoring the tumor type of non-mucinous adenocarcinoma and pT3. However, the molecular mechanisms of this tendency are unclear and more research on this topic needs to be under taken. No statistically significant association in other selected clinicopathological features were found according to KRAS genotypes. In conclusion, the current study indicated that $33.6 \%$ of 1000 colorectal cancer sample in Iranian population showed KRAS mutations. Also mutational status of KRAS was associated with high age of patients, tumor type of adenocarcinoma nonmucinous and tumor size of pT3, this is an important issue for future research.

\section{Acknowledgements}

The authors widely acknowledged the patients and their families for participation in this project. This work was supported by Iran University of Medical Sciences.

\section{References}

Ahlquist T, Bottillo I, Danielsen SA, et al (2008). RAS signaling in colorectal carcinomas through alteration of RAS, RAF, NF1, and/or RASSF1A. Neoplasia, 10, 680-6, 2 p following 686.

Allegra CJ, Jessup JM, Somerfield MR, et al (2009). American society of clinical oncology provisional clinical opinion: testing for KRAS gene mutations in patients with metastatic colorectal carcinoma to predict response to anti-epidermal growth factor receptor monoclonal antibody therapy. J Clin Oncol, 27, 2091-6. 
Amado RG, Wolf M, Peeters M, et al (2008). Wild-type KRAS is required for panitumumab efficacy in patients with metastatic colorectal cancer. J Clin Oncol, 26, 1626-34.

Andreyev HJ, Norman AR, Cunningham D, et al (2001). Kirsten ras mutations in patients with colorectal cancer: the 'RASCAL II' study. Br J Cancer, 85, 692-6.

Andreyev HJ, Norman AR, Cunningham D, et al (1998). Kirsten ras mutations in patients with colorectal cancer: the multicenter "RASCAL" study. J Natl Cancer Inst, 90 , 675-84.

Bamford S, Dawson E, Forbes S, et al (2004). The COSMIC (catalogue of somatic mutations in cancer) database and website. Br J Cancer, 91, 355-8.

Benvenuti S, Sartore-Bianchi A, Di Nicolantonio F, et al (2007). Oncogenic activation of the RAS/RAF signaling pathway impairs the response of metastatic colorectal cancers to anti-epidermal growth factor receptor antibody therapies. Cancer Res, 67, 2643-8.

Borras E, Jurado I, Hernan I, et al (2011). Clinical pharmacogenomic testing of KRAS, BRAF and EGFR mutations by high resolution melting analysis and ultra-deep pyrosequencing. BMC Cancer, 11, 406.

Bos JL, Fearon ER, Hamilton SR, et al (1987). Prevalence of ras gene mutations in human colorectal cancers. Nature, 327, 293-7.

Campbell SL, Khosravi-Far R, Rossman KL, et al (1998). Increasing complexity of Ras signaling. Oncogene, 17, 1395-413.

Chen D, Wang YY, Chuai ZR, et al (2014). High-resolution melting analysis for accurate detection of BRAF mutations: a systematic review and meta-analysis. Sci Rep, 4, 4168.

Ciardiello F, Tejpar S, Normanno N, et al (2011). Uptake of KRAS mutation testing in patients with metastatic colorectal cancer in Europe, Latin America and Asia. Target Oncol, 6, 133-45.

De Roock W, De Vriendt V, Normanno N, et al (2011). KRAS, BRAF, PIK3CA, and PTEN mutations: implications for targeted therapies in metastatic colorectal cancer. Lancet Oncol, 12, 594-603.

Deng G, Bell I, Crawley S, et al (2004). BRAF mutation is frequently present in sporadic colorectal cancer with methylated hMLH1, but not in hereditary nonpolyposis colorectal cancer. Clin Cancer Res, 10, 191-5.

Dolatkhah R, Somi MH, Bonyadi MJ, et al (2015). Colorectal cancer in iran: molecular epidemiology and screening strategies. J Cancer Epidemiol, 2015, 643020.

Farina-Sarasqueta A, van Lijnschoten G, Moerland E, et al (2010). The BRAF V600E mutation is an independent prognostic factor for survival in stage II and stage III colon cancer patients. Ann Oncol, 21, 2396-402.

Fransen K, Klintenas M, Osterstrom A, et al (2004). Mutation analysis of the BRAF, ARAF and RAF-1 genes in human colorectal adenocarcinomas. Carcinogenesis, 25, 527-33.

French AJ, Sargent DJ, Burgart LJ, et al (2008). Prognostic significance of defective mismatch repair and BRAF V600E in patients with colon cancer. Clin Cancer Res, 14, 3408-15.

Guedes JG, Veiga I, Rocha P, et al (2013). High resolution melting analysis of KRAS, BRAF and PIK3CA in KRAS exon 2 wild-type metastatic colorectal cancer. BMC Cancer, 13, 169.

Herreros-Villanueva M, Rodrigo M, Claver M, et al (2011). KRAS, BRAF, EGFR and HER2 gene status in a Spanish population of colorectal cancer. Mol Biol Rep, 38, 1315-20.

Hsieh LL, Er TK, Chen CC, et al (2012). Characteristics and prevalence of KRAS, BRAF, and PIK3CA mutations in colorectal cancer by high-resolution melting analysis in Taiwanese population. Clin Chim Acta, 413, 1605-11.
Imamura Y, Morikawa T, Liao X, et al (2012). Specific mutations in KRAS codons 12 and 13, and patient prognosis in 1075 BRAF wild-type colorectal cancers. Clin Cancer Res, 18 , 4753-63.

Janakiraman M, Vakiani E, Zeng Z, et al (2010). Genomic and biological characterization of exon 4 KRAS mutations in human cancer. Cancer Res, 70, 5901-11.

Jemal A, Bray F, Center MM, et al. (2011). Global cancer statistics. CA Cancer J Clin, 61, 69-90.

Kadowaki S, Kakuta M, Takahashi S, et al (2015). Prognostic value of KRAS and BRAF mutations in curatively resected colorectal cancer. World J Gastroenterol, 21, 1275-83.

Kwon MJ, Lee SE, Kang SY, et al (2011). Frequency of KRAS, BRAF, and PIK3CA mutations in advanced colorectal cancers: Comparison of peptide nucleic acid-mediated PCR clamping and direct sequencing in formalin-fixed, paraffinembedded tissue. Pathol Res Pract, 207, 762-8.

Li HT, Lu YY, An YX, et al (2011). KRAS, BRAF and PIK3CA mutations in human colorectal cancer: relationship with metastatic colorectal cancer. Oncol Rep, 25, 1691-7.

Mahdavinia M, Bishehsari F, Ansari R, et al (2005). Family history of colorectal cancer in Iran. BMC Cancer, 5, 112.

Malekzadeh R, Bishehsari F, Mahdavinia M, et al (2009). Epidemiology and molecular genetics of colorectal cancer in iran: a review. Arch Iran Med, 12, 161-9.

Naghibalhossaini F, Hosseini HM, Mokarram P, et al (2011). High frequency of genes' promoter methylation, but lack of BRAF V600E mutation among Iranian colorectal cancer patients. Pathol Oncol Res, 17, 819-25.

Negru S, Papadopoulou E, Apessos A, et al (2014). KRAS, NRAS and BRAF mutations in Greek and Romanian patients with colorectal cancer: a cohort study. BMJ Open, 4, 4652.

Rajagopalan H, Bardelli A, Lengauer C, et al (2002). Tumorigenesis: RAF/RAS oncogenes and mismatch-repair status. Nature, 418, 934.

Rizzo S, Bronte G, Fanale D, et al (2010). Prognostic vs predictive molecular biomarkers in colorectal cancer: is KRAS and BRAF wild type status required for anti-EGFR therapy? Cancer Treat Rev, 36, 56-61.

Roth AD, Tejpar S, Delorenzi M, et al (2010). Prognostic role of KRAS and BRAF in stage II and III resected colon cancer: results of the translational study on the PETACC-3, EORTC 40993, SAKK 60-00 trial. J Clin Oncol, 28, 466-74.

Saridaki Z, Tzardi M, Papadaki C, et al (2011). Impact of KRAS, BRAF, PIK3CA mutations, PTEN, AREG, EREG expression and skin rash in $>/=2$ line cetuximab-based therapy of colorectal cancer patients. PLoS One, 6, 15980.

Schubbert S, Shannon K, Bollag G (2007). Hyperactive Ras in developmental disorders and cancer. Nat Rev Cancer, 7, 295-308.

Simi L, Pratesi N, Vignoli M, et al (2008). High-resolution melting analysis for rapid detection of KRAS, BRAF, and PIK3CA gene mutations in colorectal cancer. Am J Clin Pathol, 130, 247-53.

Spindler KL, Lindebjerg J, Lahn M, et al (2009). Protein kinase C-beta II (PKC-beta II) expression in patients with colorectal cancer. Int J Colorectal Dis, 24, 641-5.

Vaughn CP, Zobell SD, Furtado LV, et al (2011). Frequency of KRAS, BRAF, and NRAS mutations in colorectal cancer. Genes Chromosomes Cancer, 50, 307-12.

Ye JX, Liu Y, Qin Y, et al (2015). KRAS and BRAF gene mutations and DNA mismatch repair status in Chinese colorectal carcinoma patients. World J Gastroenterol, 21, 1595-605.

Yokota T, Ura T, Shibata N, et al (2011). BRAF mutation is a powerful prognostic factor in advanced and recurrent colorectal cancer. Br J Cancer, 104, 856-62. 